\title{
GARCH Effect and Abnormal Returns during COVID-19 Pandemic
}

\author{
Elok Heniwati \\ \{elok.heniwati@ekonomi.untan.ac.id\} \\ Economic and Business Faculty, Universitas Tanjungpura, Jl. Prof. Dr. H. Hadari Nawawi, Pontianak, \\ Kalimantan Barat, Indonesia
}

\begin{abstract}
Considering that in general stock returns display time-varying volatility, researchers focus on how abnormal returns are calculated because it impacts on how it will be interpreted. This study uses a market model for the GARCH effect to obtain a more efficient estimation result. Using the sample of bank stocks, we empirically investigate how this adjustment impacts the magnitude of the abnormal return associated with the COVID-19 event. The results show that the calculation of abnormal returns taking into account the GARCH effect results in a more widespread than OLS. It suggests that the traditional market model should be sharpened for conditional heteroscedasticity when calculating abnormal returns during the COVID-19 outbreaks.
\end{abstract}

Keywords: Covid-19, Indonesia, Capital Market, GARCH, volatility

\section{Introduction}

This study aims to examine the effect of adjusting the market model for the GARCH series process in an event study methodology using a sample of stock returns during COVID-19 outbreaks. It investigates how the GARCH calculation in the market model will result in different parameter coefficients, which can lead to different interpretations of the economic significance of the impact of COVID-19 on the bank stock returns listed on the Indonesia Stock Exchange.

Economists are often asked to measure the impact of economic events or others, such as political events, disasters, and accidents [1] on the value of a firm. By using financial market data, the researchers measure the impact of a particular event on firm value or measure market efficiency through mostly the Sharpe's (1963) market model. The model explains how the return on an asset $\left(R_{s w}\right)$ is related to the return on the market portfolio $\left(R_{p w}\right)$ through the slope coefficient $\left(\beta_{s}\right)$, which represents the asset market risk (See Equation 2).

Parameters used to calculate the abnormal returns during the event being tested are usually estimated using OLS regression. However, a number of assumptions in the OLS have been debated. For example, the market model's coefficient is constant over time or that the homoscedasticity distribution of the OLS residual has a constant variance. A study has proven that the regression coefficient can vary over time resulting in differences in abnormal returns [2] and it is suggested that the impact of an event on the price of a security can be adjusted according to the presence of heteroscedasticity [3]. Meanwhile, it is stated that parameter estimation becomes inefficient and test statistics are inconsistent if it does not consider the time dependence in the stock return series [4]. Futher study shows that the return series' empirical 
characteristics can be explained by the Generalized Autoregressive Conditional Heteroscedastic $(\mathrm{GARCH})$ model as the model allows non-linear intertemporal dependence on the continuing series [5]. Furthermore, the estimation of the market model with ARCH process is more efficient in results [6] and the residuals obtained using the standard market model exhibit strong ARCH properties [7].

A number of researchers have shown that COVID-19 impacts on abnormal returns [8], [9], [10], [11]. Likewise, a study conducted by [12] found that the COVID-19 outbreak had an impact on both the Chinese and Asian stock markets as indicated by a significant decrease in cumulative abnormal return (CAR) and remained negative across all event window periods examined. These results reflect investors' expectations for the economy in the face of a contagious health virus outbreak. In contrast to previous studies, this study uses the event study method with a comprehensive model process (OLS and GARCH series) to obtain a robust result of the impact of COVID-19 on the shares of commercial bank sectors listed on the IDX. The sector was chosen because Bank Indonesia emphasized that during the economic slowdown due to COVID-19 the national banking stability did not affect. Therefore, this study was conducted to examine it from the perspective of bank financial market performance.

Much attention has been devoted to deal with the COVID-19 through various studies by examining the pandemic impact on the economy. However, most of the studies emphasize on global economic impacts and to the best authors' knowledge, none yet works of literature studied the impact of correcting the market model for the GARCH series in an event study using a sample of the Indonesia capital market during coronavirus outbreaks. This gap provides an opportunity to study that assesses the impact of the COVID-19 outbreaks on the bank stock prices in Indonesia.

\section{Literature Review}

Epidemic risk news might significantly influence investor confidence. The decrease of investor's optimism regarding future profits might result in his/her willingness to take risks. Such individual investor perceptions then spread through 'group psychology' which can eventually lead to fluctuations in the stock market. Therefore, panicked investor behavior can damage the market and reduce equity in affected stock markets [12], which will impact individual and institutional investors and lead to stock market decline in Indonesia.

"A securities market is efficient if security prices fully reflect the information available" [13]. Investors incorporate the information available in their decisions, which is reflected in their trading prices. Likewise, the health crisis that recently had turned into an economic crisis that swells amid financial difficulties are considered by investors around the world as a striking risk stirring their nervous behavior [14]. It can be seen from asset price changes because of specific events such as the COVID-19 in which the changes have declined the investors' confidence. To account for the alterations, the scientist need not trace all the imminent differences to cash flows and discount rates distinctly because asset markets provide continuing, high-stakes analyses considering future expected outcomes [15].

Volatility will have an impact on the increasing uncertainty of future returns and risks. The movement of volatility tends to be clustering in nature, that is, yesterday's high volatility will be followed by today's high volatility. Some researchers state that the ARCH/GARCH estimation model is best to describe the phenomenon since it could closely describe the real conditions and provide a simple and parsimonious model [16]. 


\section{Methodology and data analysis}

This event study employed the commercial bank and IHSG daily returns from September 9, 2019, to March 31, 2020. The data were collected from yahoofinance.com. The event $(w=0)$ referred to this study was the announcement of COVID-19 as a global pandemic by the WHO on March 13, 2020. To test the correlation between the event and abnormal returns around the event date, the bank, and IHSG closing stock prices were collected for 21 days namely 10 days before $(w-1$ to $w-10)$ and 10 days after $(w+1$ to $w+10)$ events plus a day of the event $(w=0)$. This period was called the event period or window period $(w-10, w+10)$. Next, the estimation period performed to calculate the expected return was a 100-day trading period, started from $w$ - 11 to $w-110$.

In measuring the changes or movements of the bank stock returns, the study uses the following specification:

$R_{s, w}=\ln \left(B_{s, w} /_{B_{s, w-1}}\right) x 100 \%$

where $R_{s, w}$ was the bank stock return $s$ on time $w ; B_{s, w}$, and $B_{s, w-1}$ were the bank closing price of stock $s$ on time $w$ and $w$-1, respectively. Further, four methods (OLS, MMG, MME, and MMT) to evaluate abnormal returns of a significant event were applied.

The OLS model which assumes that conditional volatilities are unvarying is as follows:

$R_{s, w}=\alpha_{s}+\beta_{s} R_{p, w}+\varepsilon_{s, w}$

$R_{p, w}=\ln \left(I H S G_{w} /_{I H S G_{w-1}}\right) \times 100 \%$

where $R_{s, w}$ was the bank stock return $s$ on time $w ; R_{p, w}$ is IHSG return on time $w . \varepsilon_{s, w}$ was the error term, where $\varepsilon_{s, w} \sim N\left(0, \sigma_{\varepsilon}^{2}\right)$, and it was expected to have zero value and constant variance; $\alpha_{s}$ and $\beta_{s}$ were coefficients of regression, the intercept, and systematic risk, respectively, referring to the sensitivity level of the bank stock price $s$ changes compared to changes in market share prices (IHSG).

This study also performs a market model with the GARCH (MMG) process as an alternative model for the conditional variance of bank stock returns. Henceforth, the error term, $\varepsilon_{s, w}$, (See Equation 2) was defined as $\varepsilon_{s, w} \mid \theta_{w-1} \sim N\left(0, h_{s, w}\right)$ and the structure is:

$h_{o, w}=\partial_{s}+\alpha_{s} h_{s, w-1}+\beta_{s} \varepsilon_{s, w-1}^{2}$,

where $h_{s, w}$ was conditional of the error variance $\varepsilon_{s, w}$, which depended on the current information on day $\theta_{w-1} ; q$ was the number of lags of $\varepsilon_{s, w}$ and $p$ was the number of lags of $h_{s, w}$; parameters $\alpha$ and $\beta$ indicated the sensitivity of $h_{s, w}$ to the lag squared $\varepsilon_{s, w}$ and $h_{s, w}$ itself; and $\partial_{s}>0, \beta_{s}>$ $0, \alpha_{s} \geq 0$ and $\beta_{s}+\alpha_{s}<0$.

The asymmetric effect of information was frequently considered in the stock market. In the stock market, higher volatility generally followed the movements that decreased than the movements that increased for the same magnitude [17]. The GARCH framework did not effectively explain the asymmetric information attributes. As a result, this study performed the Threshold GARCH (MMT) [18] and Exponential GARCH (MME) [19] to measure asymmetry effects.

In the MME model, the variance equation carried out a logarithmic function to capture the asymmetric effects in time series data. Thus, the structure of the conditional variance equation using $\operatorname{MME}(p, q)[20]$ was:

$\log h_{s, w}=\left\{\partial_{s}+\sum_{t=1}^{q}\left(\alpha_{s, t}\left|\frac{\varepsilon_{s-t}}{h_{s, w-t}^{1 / 2}}\right|+\delta_{s, t} \frac{\varepsilon_{w-t}}{h_{s, w-t}^{1 / 2}}\right)+\sum_{u=1}^{p} \beta_{s, u} \ln \left(h_{s, w-u}\right)\right\}$, 
where $\delta$ parameter was the asymmetric effect on the conditional variance $h_{w}$, and the asymmetry occurred if $\neq 0$. Then, the conditional variance equation for $\operatorname{MMT}(p, q)$ process is:

$h_{s, w}=\partial_{s}+\sum_{s=1}^{q} \alpha_{s, t} \varepsilon_{s, w-t}^{2}+\delta_{s} \varepsilon_{s, w-1}^{2} D_{s, w-1}+\sum_{u=1}^{p} \beta_{s, u} h_{s, w-u}$

where $\delta$ parameter was the asymmetric effect on the conditional variance, $h_{w}$, and the asymmetry occurred because of the inclusion of dummy variable, $D$, which was equal to 1 if $\varepsilon_{w-1} \leq 0$ and 0 otherwise. This estimation made it possible to analyze different conditions to exhibit different event, that is positive or negative reactions that differ in volatility.

Using the OLS, $\operatorname{MMG}(1,1), \operatorname{MME}(1,1)$ and $\operatorname{MMT}(1,1)$ approach, the regression coefficients can be estimated (see Eq. 2) to measure changes in abnormal returns in the event period as follows:

$H\left(R_{s, w}\right)=\hat{\alpha}_{s}+\hat{\beta}_{s} R_{p, w}$

where $H\left(R_{s, w}\right)$ was expected returns of the bank stock $s$ on time $w ; R_{s, w}$, and $R_{p, w}$ was the bank stock $s$ and market (IHSG) returns, respectively, on time $w$. The result was then employed to calculate the abnormal returns of the bank stock during the event period:

$A R_{s, w}=R_{s, w}-H\left(R_{s, w}\right)$

where $A R_{s, w}$ was the abnormal return of the bank stock $s$ on time $w$.

Next, the cumulative abnormal returns of the bank stock $s$ were computed for a 21-day event period by combining the abnormal return of the bank stock $s$ periods from $D_{I}$ to $D_{d}$ in the event period. The equation formula was as follows:

$C A R_{S\left(D_{1}, D_{d}\right)}=\sum_{w=D_{1}}^{D_{d}} A R_{S, w}$

where $C A R_{s, D}$ was the cumulative abnormal return of the bank stock $s$ on time $D$.

Finally, the cross-sectional average abnormal returns and cumulative average abnormal returns for a sample of $n$ stocks over the event period were calculated as follows:

$A A R_{w}=\frac{\sum_{s=1}^{N} A R_{S, w}}{N}$

$\operatorname{CAAR}_{D_{1}, D_{d}}=\frac{\sum_{l-1}^{N} C A R_{l,\left(D_{1}, D_{d}\right)}}{N}$

and $N$ was the number of bank industries.

This nonparametric event study carried out the generalized sign and the rank approaches in testing the cumulative abnormal return of the bank shares in the event period. In this study, the application of test statistics for $\left(H_{0}\right)$ and $\left(H_{1}\right)$ was as follows:

$H_{0}: C A R_{\left(D_{1}, D_{d}\right)}=0$

$H_{1}: C A R_{\left(D_{1}, D_{d}\right)} \neq 0$

Generalized sign test

Test statistics for CAR of the bank shares were based on a 100-day estimation period of abnormal returns. Thus, the equation can be stated as follows:

$\hat{p}=\frac{1}{n} \sum_{s=1}^{n} \frac{1}{100} \sum_{w=P E_{w}}^{P E_{100}} C A R_{s, w}$

where $C A R_{s, w}=\left\{\begin{array}{cc}1 \text { if } A R_{s, w}>0 \\ 0 & \text { otherwise }\end{array}\right\}$

Test statistics performed the regular estimation of the binomial distribution with the parameter $\bar{p}$. Assuming that $X$ is the bank shares with positive CAR in the event period, $C A R_{X,\left(D_{1}, D_{d}\right)}$, the generalized sign test statistics were stated as follows:

$Z_{G}=\frac{X-n \hat{p}}{[n \hat{p}(1-\hat{p})]^{1 / 2}}$ 


\section{Result and Discussion}

After calculating the abnormal returns of an individual sample firm, overall values were totaled, and the average was calculated to generate the average abnormal return (AAR). Further, the CAAR individual company was calculated by adding the AAR value during the event period. Table 1 displays the AAR and CAAR.

Table 1. AAR and CAAR across Window Event $t-10, t+10(\%)$

\begin{tabular}{lrlllllll}
\hline Event & \multicolumn{3}{c}{ Average Abnormal Returns } & \multicolumn{3}{c}{ Cumulative Average Abnormal Returns } \\
Period & OLS & MMG & MME & MMT & OLS & MMG & MME & MMT \\
\hline$t-10$ & 0.001 & $\mathbf{- 0 . 1 6 2}$ & -0.035 & $\mathbf{- 0 . 1 0 4}$ & 0.001 & -0.162 & -0.035 & -0.104 \\
$t-9$ & -0.006 & $\mathbf{- 0 . 1 6 8}$ & -0.044 & $\mathbf{- 0 . 1 1 0}$ & -0.005 & -0.330 & -0.079 & -0.213 \\
$t-8$ & -0.011 & $\mathbf{- 0 . 1 7 5}$ & -0.047 & $\mathbf{- 0 . 1 1 7}$ & -0.016 & -0.506 & -0.126 & -0.330 \\
$t-7$ & 0.000 & $\mathbf{- 0 . 1 6 3}$ & -0.036 & $\mathbf{- 0 . 1 0 5}$ & -0.016 & -0.669 & -0.162 & -0.435 \\
$t-6$ & 0.006 & $\mathbf{- 0 . 1 6 3}$ & -0.021 & $\mathbf{- 0 . 1 0 5}$ & -0.010 & -0.832 & -0.183 & -0.540 \\
$t-5$ & 0.018 & $\mathbf{- 0 . 1 5 1}$ & -0.010 & $\mathbf{- 0 . 0 9 3}$ & 0.008 & -0.982 & -0.193 & -0.633 \\
$t-4$ & 0.013 & $\mathbf{- 0 . 1 5 2}$ & -0.020 & $\mathbf{- 0 . 0 9 4}$ & 0.021 & -1.135 & -0.213 & -0.727 \\
$t-3$ & -0.005 & $\mathbf{- 0 . 1 6 8}$ & -0.043 & $\mathbf{- 0 . 1 0 9}$ & 0.016 & -1.302 & -0.256 & -0.836 \\
$t-2$ & -0.013 & $\mathbf{- 0 . 1 7 0}$ & $\mathbf{- 0 . 0 5 9}$ & $\mathbf{- 0 . 1 1 0}$ & 0.003 & -1.472 & -0.315 & -0.946 \\
$t-1$ & 0.010 & $\mathbf{- 0 . 1 5 7}$ & -0.019 & $\mathbf{- 0 . 0 9 9}$ & 0.014 & -1.630 & -0.334 & -1.045 \\
$t=\mathbf{0}$ & -0.014 & $\mathbf{- 0 . 1 7 8}$ & -0.049 & $\mathbf{- 0 . 1 1 9}$ & 0.000 & -1.808 & -0.383 & -1.165 \\
$t+1$ & -0.020 & $\mathbf{- 0 . 1 7 9}$ & $\mathbf{- 0 . 0 6 3}$ & $\mathbf{- 0 . 1 2 0}$ & -0.021 & -1.987 & -0.447 & -1.285 \\
$t+2$ & 0.001 & $\mathbf{- 0 . 1 6 5}$ & -0.031 & $\mathbf{- 0 . 1 0 7}$ & -0.020 & -2.152 & -0.478 & -1.392 \\
$t+3$ & -0.005 & $\mathbf{- 0 . 1 6 6}$ & -0.047 & $\mathbf{- 0 . 1 0 6}$ & -0.025 & -2.317 & -0.525 & -1.498 \\
$t+4$ & -0.006 & $\mathbf{- 0 . 1 6 5}$ & -0.049 & $\mathbf{- 0 . 1 0 6}$ & -0.031 & -2.483 & -0.574 & -1.604 \\
$t+5$ & -0.011 & $\mathbf{- 0 . 1 7 3}$ & -0.049 & $\mathbf{- 0 . 1 1 4}$ & -0.041 & -2.655 & -0.623 & -1.718 \\
$t+6$ & -0.008 & $\mathbf{- 0 . 1 6 7}$ & -0.051 & $\mathbf{- 0 . 1 0 8}$ & -0.049 & -2.822 & -0.674 & -1.825 \\
$t+7$ & -0.008 & $\mathbf{- 0 . 1 7 6}$ & -0.036 & $\mathbf{- 0 . 1 1 8}$ & -0.057 & -2.998 & -0.710 & -1.943 \\
$t+8$ & 0.001 & $\mathbf{- 0 . 1 5 9}$ & -0.042 & $\mathbf{- 0 . 0 9 9}$ & -0.056 & -3.156 & -0.752 & -2.043 \\
$t+9$ & 0.010 & $\mathbf{- 0 . 1 5 4}$ & -0.026 & $\mathbf{- 0 . 0 9 6}$ & -0.046 & -3.311 & -0.778 & -2.139 \\
$t+10$ & -0.002 & $\mathbf{- 0 . 1 7 9}$ & -0.015 & $\mathbf{- 0 . 1 2 3}$ & -0.048 & -3.490 & -0.793 & -2.262 \\
\hline $\mathbf{N}$ & & & & & & & &
\end{tabular}

Notes. The total sample is 41 banks. The table represents the average abnormal returns and the cumulative average abnormal returns over the 21 -day window period, i.e., 10 days before and 10 days after the event date (the announcement date of the coronavirus as a global pandemic by the WHO). Abnormal returns are measured by subtracting the expected return from actual returns. The $\alpha$ and $\beta$ parameters for calculating the expected return are determined by the traditional market model (OLS) and the market model with GARCH process (MMG [1,1], MME [1,1], MMT [1,1]). The standard t-test statistic is used to test the null hypothesis, which states that abnormal returns are zero.

It can be seen from Table 1, that AAR using OLS is not statistically significant. This state is inversely relative to the AAR calculated by the $\operatorname{MMG}(1,1)$ and $\operatorname{MMT}(1,1)$ processes, which indicate that AAR during the window period $t-10, t+10$ is statistically significant. Meanwhile, by calculating with the MME process $(1,1)$, AAR is only significant at times $t-2(-0.059)$ and $t+$ $1(-0.063)$. It means that the public or the market may have anticipated that the world health crisis will threaten the Indonesia economy.

Turning to the column presenting the CAAR results from the sample bank. It can be seen that the CAAR calculation using the traditional OLS process shows relatively stable results. There is a positive CAAR from $t-5$ to $t=0$, followed by a negative CAAR until the end of the 
window. Meanwhile, the CAAR calculated by the process of GARCH shows the same pattern, which increases with negative results that are getting sharper at the end of the window period.

Fig. 1 depicts the movement of AAR over the 21 day window period of the sample banks calculated by the traditional method (OLS) and by the GARCH process (MMG, MMT, MME). The AAR result from the OLS process calculation shows a fluctuating pattern around the zero value. It starts with a negative result, but the trend becomes positive as it approaches Day 0 or the announcement date. The trend returns negative after day 0 until the end of the window period. Meanwhile, the AAR movement calculated by the process of GARCH (MMG, MMT, and MME) shows negative results from the beginning to the end of the window period. This situation confirms the results presented in Table 1 above.

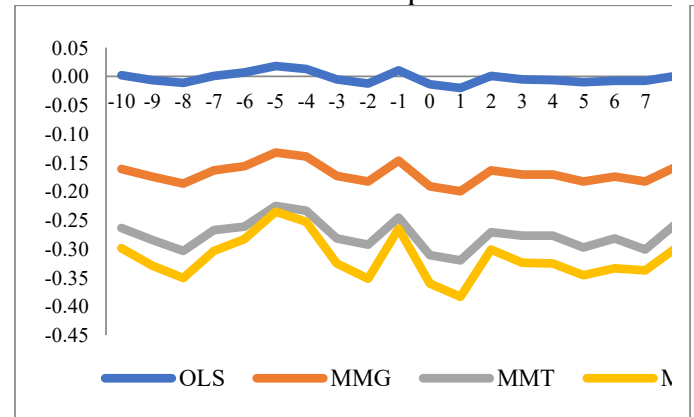

Fig. 1. The bank's AAR comparison around COVID-19 outbreaks

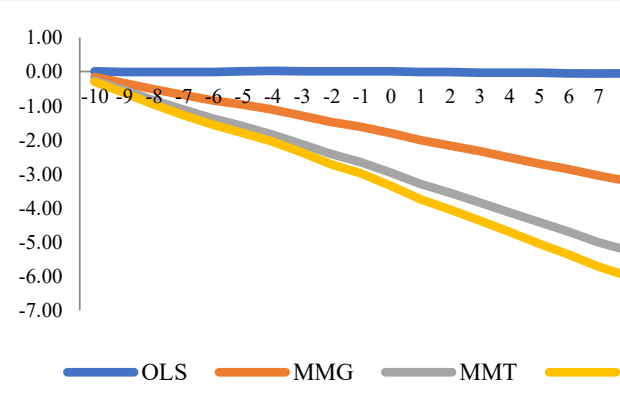

Fig. 2. The bank's CAAR comparison around COVID-19 outbreaks

It can be observed that the CAAR between the OLS and serial GARCH models has a different pattern (see Fig. 2). The OLS model shows a typical pattern close to zero. On the other hand, the third pattern of the GARCH series (MMG, MMT, and MME) goes further from zero at the end of the window period. In other words, the abnormal return rate gets more negative as the number of days increases during the window period. The MME pattern shows the sharpest decline, followed by MMT and MMG.

The presence of GARCH does not violate the second-order property assumptions of the OLS estimator. However, the difference in the abnormal return is due to inefficiency in the estimation of alpha and beta parameters obtained using the market model that does not adjust for the GARCH effect. When market model residuals are tested for ARCH's existence, reliable evidence of the property of ARCH is revealed. MMG solves this problem, and its estimators are more efficient as a result. Furthermore, the MMG model's suitability was confirmed because all firms had statistically significant estimated GARCH parameters from the alpha and beta coefficients, and the number was also less than one unit.

\section{Conclusion}

This paper aims to estimate the market model parameters adjusted for the GARCH effect. Using a sample of banking industry stocks, researchers found that adjustments for GARCH affect the abnormal returns associated with the COVID-19 plagues thus can lead to different interpretations of their economic significance.

This current study enriches existing literature about the pandemic impact on the economy and contributes facts for knowledge in finance and economics. Further research may apply a different large sample to gain robust results. 


\section{References}

[1] C. Chang, S. Hsu, and M. McAleer, "An event study analysis of political events, disasters, and accidents for Chinese tourists to Taiwan," Sustainability, vol. 10, no. 4307, pp. 1-77, 2018.

[2] Z. Iqbal and P. L. Dheeriya, "A comparison of the market model and random coefficient model using mergers as an event," J. Econ. Bus., vol. 43, no. 1, pp. 87-93, 1991.

[3] C. Giaccoto and M. M. Ali, "Optimal distribution free tests and further evidence of heteroskedasticity in the market model," J. Finance, vol. 37, pp. 1247-1257, 1982.

[4] A. Corhay and A. T. Rad, "Conditional heteroskedasticity adjusted market model and an event study,” Q. Rev. Econ. Financ., vol. 36, no. 4, pp. 529-538, 1996.

[5] T. Bollerslev, "Generalized autoregressive conditional heteroscedasticity," J. Econom., vol. 31 , pp. 307-327, 1986.

[6] A. Bera, E. Bubnys, and H. Park, "Conditional heteroscedasticity in the market model and efficient estimates of betas," Financ. Rev., vol. 23, pp. 201-214, 1988.

[7] F. X. Diebold, J. Im, and C. J. Lee, "Conditional heteroscedasticity in the market," Washington, DC, 1988.

[8] B. N. Ashraf, "Research in International Business and Finance Stock markets' reaction to COVID-19: Cases or fatalities ?," Res. Int. Bus. Financ., vol. 54, no. May, p. 101249, 2020.

[9] D. Zhang, M. Hu, and Q. Ji, "Financial markets under the global pandemic of COVID-19," Financ. Res. Lett., no. April, p. 101528, 2020.

[10] M. Mazur, M. Dang, and M. Vega, "COVID-19 and the march 2020 stock market crash. Evidence from S\&P1500," Financ. Res. Lett., no. July, p. 101690, 2020.

[11] M. Ali, N. Alam, and S. A. R. Rizvi, "Coronavirus (COVID-19) — An epidemic or pandemic for financial markets," J. Behav. Exp. Financ., vol. 27, p. 100341, 2020.

[12] H. Liu, Y. Wang, D. He, and C. Wang, "Short term response of Chinese stock markets to the outbreak of COVID-19," Appl. Econ., 2020.

[13] E. F. Fama, "Efficient capital markets: A review of theory and empirical work," $J$. Finance, no. May, pp. 383-306, 1970.

[14] S. Ramelli and A. F. Wagner, "Feverish Stock Price Reactions to COVID-19," 2020.

[15] G. W. Schwert, "Using financial data to measure effects of regulation," J. Law Econ., vol. 24, pp. 121-158, 1981.

[16] Y. Wei, Y. Wang, and D. Huang, "Forecasting crude oil market volatility : Further evidence using GARCH-class models," Energy Econ., vol. 32, no. 6, pp. 1477-1484, 2010.

[17] R. Engle and V. K. Ng, "Measuring and Testing the Impact of News on Volatility," $J$. Finance, vol. 48, no. 5, pp. 1749-1778, 1993.

[18] L. R. Glosten, R. Jagannathan, and D. E. Runkle, "On the Relation between the Expected Value and the Volatility of the Nominal Excess Return on Stocks," J. Finance, vol. 48, no. 5, pp. 1779-1801, 1993.

[19] D. B. Nelson, "Conditional Heteroskedasticity in Asset Returns: A New Approach," Econometrica, vol. 59, no. 2, pp. 347-370, Apr. 1991.

[20] M. H. Chen, S. C. (Shawn) Jang, and W. G. Kim, "The impact of the SARS outbreak on Taiwanese hotel stock performance: An event-study approach,” Int. J. Hosp. Manag., vol. 26, no. 1, pp. 200-212, 2007. 